\title{
Un nuevo lingote de plomo de Q. Haterius Gallus y la participación de la gens Hateria en la explotación de las minas de Sierra Morena
}

\author{
A new lead ingot of Q. Haterius Gallus and the \\ participation of the gens Hateria in the exploitation \\ of the Sierra Morena mines
}

\author{
Alejandro G. Sinner \\ University of Victoria. Greek and Roman Studies \\ 3800 Finnerty Road, Clearihue B423, CAN-Victoria, BC \\ agsinner@uvic.ca
}

En este artículo presentamos un lingote de plomo inédito procedente de la Colección Guerra (Rosas, Girona) con el sello latino Q $\bullet$ HATERI•GALLI. Sobre la base de su tipología, paleografía y características formales, parece datar de inicios del siglo i d. C. El presente trabajo incluye un estudio tipológico y epigráfico de dicho lingote, además de la caracterización isotópica del metal con que fue elaborado. En este sentido, los análisis llevados a cabo revelaron que el plomo empleado tiene su origen en el distrito minero de Sierra Morena, confirmando allí la explotación minera de Q. Haterius Gallus. El estudio prosopográfico de la gens Hateria permite sugerir la posibilidad de que Q. Haterius, cónsul sufecto en el año 5 a. C. y yerno de M. Vipsanius Agrippa, hubiese participado en la explotación de las minas de Sierra Morena. Finalmente, pese a que no podemos adscribir con certeza el lingote objeto de estudio a ningún pecio concreto, proponemos la hipótesis de que el lingote originalmente hubiera formado parte del cargamento transportado por el Cabrera 5, que naufragó en las costas de Mallorca. 
This article presents an unpublished Roman lead ingot from the Guerra collection (Roses, Girona) with a Latin stamp that reads Q $\bullet$ HATERI $\bullet$ GALLI. Based on its typological, paleographic and formal characteristics, it should be dated to the early lst century CE. The article includes a typological and epigraphic study of the ingot in addition to an isotope characterization of the metal. The analysis has revealed that the metal of the ingot has its origin in the mining district of Sierra Morena, confirming that the mining enterprises of Q. Haterius Gallus were located there. The prosopographic study of the gens Hateria allows us to suggest the possibility that Q. Haterius, Consul Suffectus in 5 BCE, and son-in-law of M. Vipsanius Agrippa, could have participated in the exploitation of the Sierra Morena mines. Finally, although the ingot cannot definitely be assigned to a specific wreck, we propose the hypothesis that the ingot had originally been part of the cargo transported by Cabrera 5, which was shipwrecked on the coasts of Majorca.

\section{KEYWORDS}

HISPANIA, LEAD ISOTOPES, EPIGRAPHY, INGOT, MINING, HATERII, AGRIPPA

\section{Introducción}

En este trabajo presentamos una pieza de interés histórico y arqueológico que actualmente forma parte de los fondos de la Colección Guerra, la cual abarca diferentes períodos históricos y cuenta con más de doscientos objetos de época clásica (mayoritariamente pertenecientes a los siglos II a. C. - I d. C.). La manera en que esta colección fue reunida resulta de gran interés para contextualizar el lingote objeto de estudio. La mayoría de los ejemplares de época romana que la componen fueron adquiridos por Esteve Guerra i Marès (1911-1988), que compraba ánforas y otros hallazgos subacuáticos a los pescadores y buceadores que los encontraron. Esto permite ubicar con cierta fiabilidad muchos de los objetos recuperados, en las aguas del Alto Ampurdán. Adicionalmente, el Museu d'Arqueologia de Catalunya declaró y catalogó en su día todas las piezas de la mencionada colección, y algunas han sido publicadas posteriormente (Martín Menéndez, 2008; Ferrer i Jané y Sinner, 2019; Sinner y Ferrer i Jané, 2020). Ello permite asociar un gran número de los objetos de la Colección Guerra, mayoritariamente ánforas, a pecios específicos, como los de Cala Bona I, Punta Blanca, Portaló/Clapera y Calella I. Desafortunadamente, resultó imposible establecer el lugar en que el lingote fue originalmente encontrado y, por tanto, desconocemos su procedencia. No obstante, tenemos la casi total certeza de que no se puede relacionar con ninguno de los pecios mencionados anteriormente. El hecho de que la colección arqueológica no incorporase piezas nuevas — numismática aparte- desde hace aproximadamente cuarenta años nos facilita un término ante quem, c. 1978, en el que el lingote en cuestión pudo pasar a formar parte de sus fondos. Hablamos personalmente con algunos pescadores y buceadores que vendieron gran parte de las piezas a Esteve Guerra, y sus testimonios confirman las hipótesis anteriores.

La que nos ocupa es una pieza de gran valor científico dentro del extenso corpus de lingotes de plomo de época romana, puesto que, a día de hoy, tan solo se conoce otro 
ejemplar con sello Q•HATERI•GALLI (Colls et al., 1986: 53 y fig. 6, n. ${ }^{\circ}$ 5) procedente del pecio Cabrera 5 (Mallorca) (Colls et al., 1986; Domergue, 2004). La aparición de un segundo lingote de este productor permite comparar ambos ejemplares, sus características, sellos y resellos, además de llevar a cabo una caracterización isotópica del plomo con el fin de obtener un mejor conocimiento de esta serie de lingotes, su cronología, producción y comercialización.

Finalmente, resulta necesario indicar que este lingote, muy posiblemente, sea uno de los expoliados durante las excavaciones del mencionado pecio. Muchos indicios apuntan en esta dirección: la tipología, las marcas, los análisis de isótopos y la fecha aproximada en que se considera que el lingote ingresó en la colección, y que coincide con la de las excavaciones. Debemos recordar que al menos 10 lingotes fueron extraídos ilegalmente del Cabrera 5 entre dos de las campañas de excavación (Colls et al., 1986: 33-34). Dos de ellos se localizaron más tarde en el Museo Arqueológico de Madrid, y otros dos en una colección privada de Sevilla. El lingote de la Colección Guerra podría ser otra pieza de este cargamento identificada 35 años más tarde.

\section{Descripción y tipología}

El lingote tiene forma rectangular, sección trapezoidal y un acabado semicircular en el dorso. Con un peso total de 40,65 kg, presenta las siguientes medidas: $450 \mathrm{~mm}$ de longitud, $122 \mathrm{~mm}$ de altura y $103 \mathrm{~mm}$ de anchura en la base (fig. 1). Podemos afirmar que su estado de conservación es bueno, ya que no muestra un excesivo grado de corrosión ni concreciones marinas importantes. Con todo, resulta posible apreciar una delgada película gris, producto de la oxidación del metal, en algunas áreas. Por tanto, no cabe duda de que estamos ante un hallazgo subacuático.

Tipológicamente hablando, su clasificación no resulta problemática: considerando sus características formales, puede adscribirse al tipo I de Domergue (1990: 253; Domergue y Rico, 2018: 216), normalmente datado entre finales del período republicano e inicios del alto Imperio.

Las dimensiones de los lingotes del tipo I suelen ser bastante uniformes y no varían demasiado entre sí —aunque se han propuesto excepciones (Díaz Ariño, 2006: 291)—, con una longitud siempre cercana a $450 \mathrm{~mm}$ y altura de entre 110 y $120 \mathrm{~mm}$, mientras que el peso oscila entre 32 y $49 \mathrm{~kg}$. Estas cifras cuadran bien con las dimensiones y el peso de la pieza objeto de estudio (fig. 1), peso que parece indicar que debería fecharse ya en época imperial, puesto que los lingotes del tipo I de época republicana normalmente están en torno a las 100 libras romanas de peso, mientras que estas cifras aumentarán considerablemente en los lingotes fundidos a principios de la época imperial, alcanzando las 170 libras (Laubenheimer, 1973: 173-179; Domergue, 1994: 62-63; Domergue y Rico, 2018: 216). 

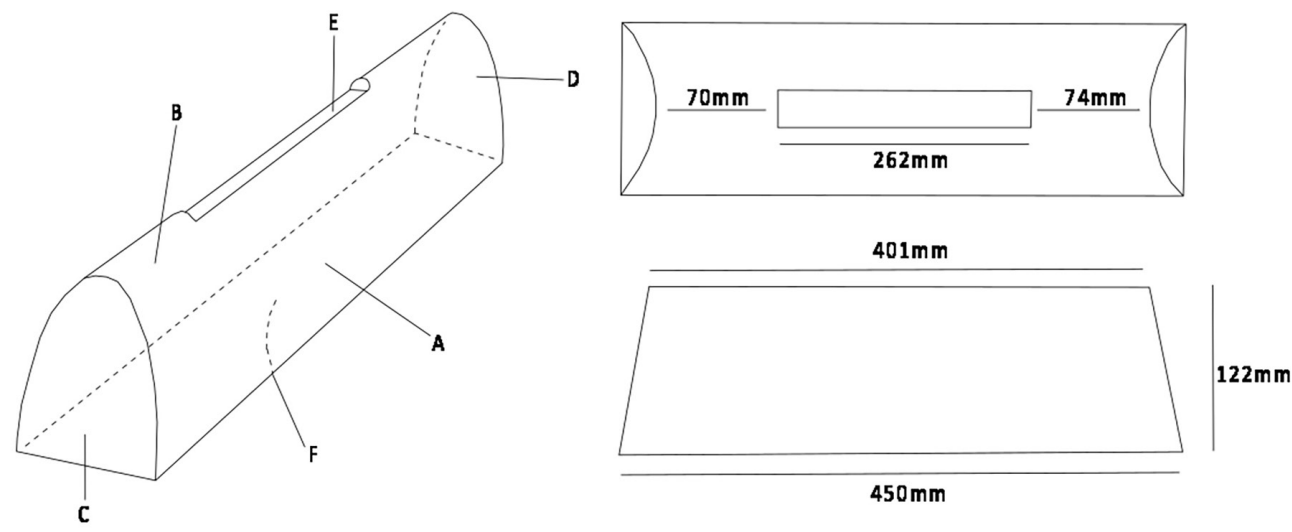

Figura 1. Esquema con las medidas del lingote y nomenclaturas de todas sus partes como se describen en el texto (Colls et al., 1986: fig. 3, adaptada por el autor).

Como ocurre con otros ejemplares del tipo I, nuestro lingote presenta ciertas características de fabricación que vale la pena describir. En las caras largas (fig. 2) se aprecian unas líneas horizontales y casi paralelas entre sí. Este fenómeno, definido como estratificación o laminación (Whittick, 1961: 106), ya se documentó con anterioridad en lingotes de plomo de las mismas tipología y cronología (Colls et al., 1986: 36). Una explicación para esta particularidad podría ser el hecho de que el metal se encontraba a una temperatura inferior a los 450-500 ${ }^{\circ} \mathrm{C}$ en el momento en que se vertió en el molde y, al entrar en contacto con el mismo, se enfrió rápidamente, creando tales líneas. Estos trazos no solo indican la temperatura a que el metal se vertió — cuanto más baja, más gruesas e irregulares son las estrías-, sino también que el molde se rellenó de forma ininterrumpida (Whittick, 1961: 106). Además, se aprecian hasta dos perforaciones de sección cuadrangular de $15 \mathrm{~mm}$ de lado que atraviesan totalmente el lingote, creando sendas aberturas en la base del mismo. Ambas perforaciones se ubican a $20 \mathrm{~mm}$ del borde. La primera se encuentra en la esquina inferior izquierda de la cara C, mientras que la segunda está localizada en el lado derecho de la cara A (figs. 1 y 2). Perforaciones similares pueden observarse en una serie de lingotes descubiertos en el pecio Lavezzi 1 (Bebko, 1971: 4, lám. XVIII), Sud Perduto 2 y en varios del Cabrera 5 (Colls et al., 1986: 37-39; Domergue, 2004: 106), entre otros. Se han propuesto cuatro posibles explicaciones para este tipo de perforaciones: una marca de control, el resultado de algún tipo de muestreo, agujeros de fijación o amarre y, finalmente, agujeros de clavo, opción esta última por la que diversos autores se han decantado (Bebko, 1971: 4; Colls et al., 1986: 39). La ausencia repetida de marcas de oxidación en tales cavidades —como también ocurre en nuestro lingote, que se inspeccionó con la ayuda de un microscopio electrónico portátil - apunta a que los clavos, si es que esa fue su función, ya habían sido retirados en el momento en que el barco se hundió (Domergue, 1994, 1998, 2004: 106). 


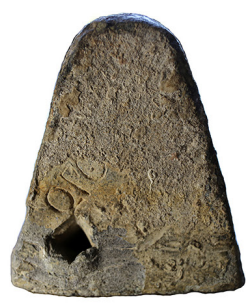

A

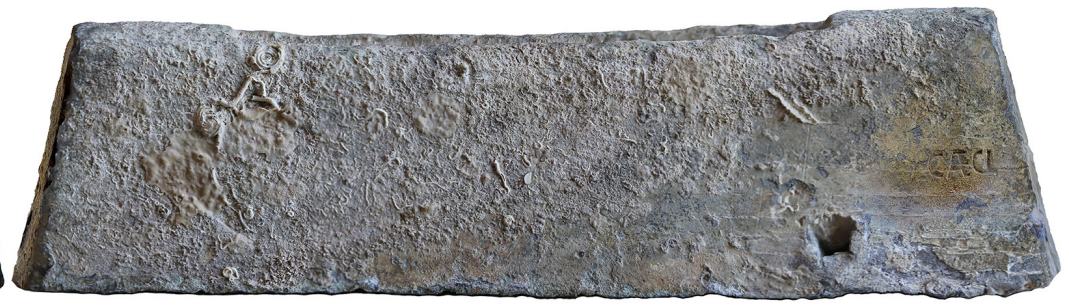

$\mathrm{C}-\mathrm{CO}=\mathrm{C}$
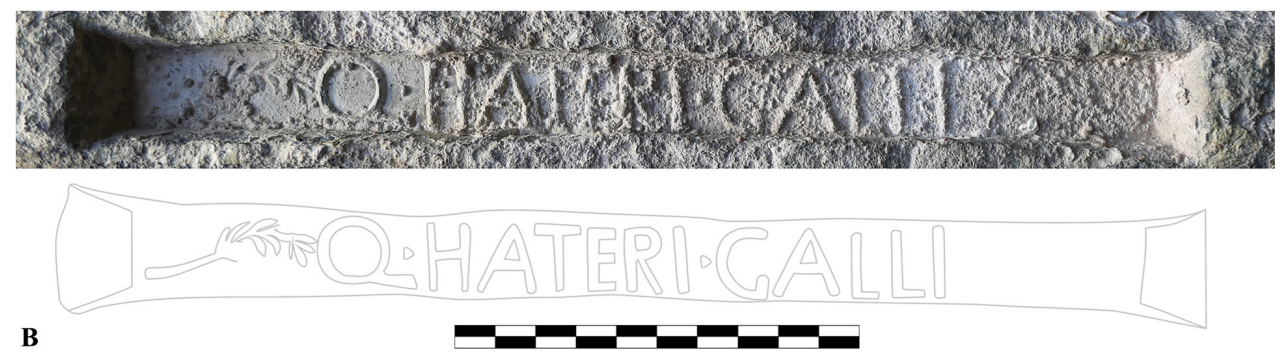

Figura 2. A) Caras $\mathrm{C}$ y $\mathrm{A}$ del lingote, en las que se pueden apreciar las perforaciones y resellos mencionados en el texto. B) Fotografía y dibujo de la cartela del lingote con el sello Q•HATER|•GALLI.

Es bien sabido que los lingotes de plomo romanos comúnmente presentan entre una, como es nuestro caso, y tres cartelas rectangulares ubicadas en el dorso de forma longitudinal. A diferencia de los resellos, que discutiremos más adelante, tales cartelas son el resultado directo del proceso de fabricación de la pieza, pues se graban en negativo en el molde cerámico en que el lingote será posteriormente fundido. Aun así, el ancho de los cartuchos se ve sujeto a variaciones de tamaño, pero normalmente, cuando solo presentan uno, suele oscilar entre 180 y $300 \mathrm{~mm}$ de longitud. Se trata de cifras que, una vez más, cuadran con los $260 \mathrm{~mm}$ (250 de espacio interior) de longitud por $22 \mathrm{~mm}$ de anchura documentados para la cartela principal de nuestra pieza.

\section{La epigrafía}

El lingote objeto de estudio presenta un total de tres marcas: el sello principal, palma $\mathrm{Q} \bullet \mathrm{HATERI} \bullet \mathrm{GALLI}$ palma, se ubica en una cartela colocada oblicuamente en la parte superior central del dorso, mientras que los dos resellos Q $\bullet P O M$ o Q $\bullet P O M[P]$ y Q $\bullet$ CÂĈ̂IL se localizan en la cara $\mathrm{C}$ del lingote y a media altura en el extremo derecho de la cara $\mathrm{A}$, respectivamente. A continuación, repasaremos cada una de estas marcas, todas ya bien conocidas, de forma individualizada. 


\subsection{Q•HATERI•GALLI}

Este tria nomina ubicado entre dos palmas debe desarrollarse como (palma) Q(uinti) Hateri(i) Galli (palma) e interpretarse como el nombre o denominación del productor del metal, independientemente de que este fuera un individuo concreto, un negocio familiar o una auténtica societas (Domergue, 1990: 253-268). Por tanto, parece fuera de toda duda que el sello Q $\bullet$ HATERI $\bullet$ GALLI hace referencia al beneficiario de la explotación minera. Si nos centramos en los detalles del mismo, el praenomen y el nomen se encuentran separados por un punto de tendencia circular, al igual que el nomen y el cognomen. Las letras son muy regulares y están impresas con claridad, lo que facilita su lectura. Por lo que se refiere al tamaño, presentan una altura media aproximada de $20 \mathrm{~mm}$ y ocupan un espacio total de $119 \mathrm{~mm}$ dentro de la cartela.

El gentilicio Haterius no es habitual en Hispania y tampoco aparece en los corpora onomásticos (Abascal, 1994), de modo que resulta relativamente sencillo localizar la actividad de los Haterii geográficamente hablando. Tan solo conocemos tres inscripciones que mencionen Haterii en la península ibérica — cuatro contando nuestro lingote- y dos de ellas, las que no provienen de hallazgos subacuáticos, se ubican en Andalucía. ${ }^{1}$ La primera de las inscripciones terrestres se encuentra en Itálica (Santiponce), pero se trata de una marca sobre un ánfora: M(arci) HA(¿teri?) S, y por lo tanto no puede relacionarse directamente con la actividad minera. La segunda de las inscripciones, por el contrario, resulta de gran interés. Menciona a un individuo llamado L•HAT(erius) y fue hallada en Martos (Jaén), a unos 40 kilómetros del distrito minero de Linares-La Carolina $\left(C I L, \mathrm{II}^{2} / 5,112\right)$, lo que ha permitido sugerir que las minas de galena explotadas por nuestro Haterius Gallus debían de formar parte del distrito minero de Sierra Morena (Colls et al., 1986: 53). La tercera y última inscripción se corresponde con un lingote de la misma serie procedente del pecio Cabrera 5, cuestión que ya hemos comentado con anterioridad. Con todo, la hipótesis de que la explotación minera de los Haterii estuviera situada en Sierra Morena necesitaba pruebas más sólidas para poder confirmarla, por lo que, en su día —al igual que hemos hecho en este estudio—, se llevó a cabo la caracterización isotópica del metal utilizado (Trincherini et al., 2001). Si retomamos la onomástica de los Haterii, vemos que son mucho más comunes en Italia —concretamente, en las zonas del Lacio y la Campania (Colls et al., 1986: 53; sobre la conexión CampaniaHispania, véase entre otros Díaz Ariño, 2008; Stefanile, 2017; Stannard et al., 2019) - y, especialmente, en la provincia de Africa Proconsularis. Por otro lado, el cognomen Gallus es bastante frecuente en África y en la península ibérica (Kajanto, 1965: 50-51; Abascal, 1994).

\subsection{Q•CÂEĈ̂IL}

Se trata del primero de los dos resellos que presenta nuestro lingote, y no aparece en relieve en este caso, sino estampado en negativo sobre el metal en frío (fig. 3). Como se

1. Epigraphik-Datenbank Clauss / Slaby EDCS. Consulta realizada el 30-07-2019. 

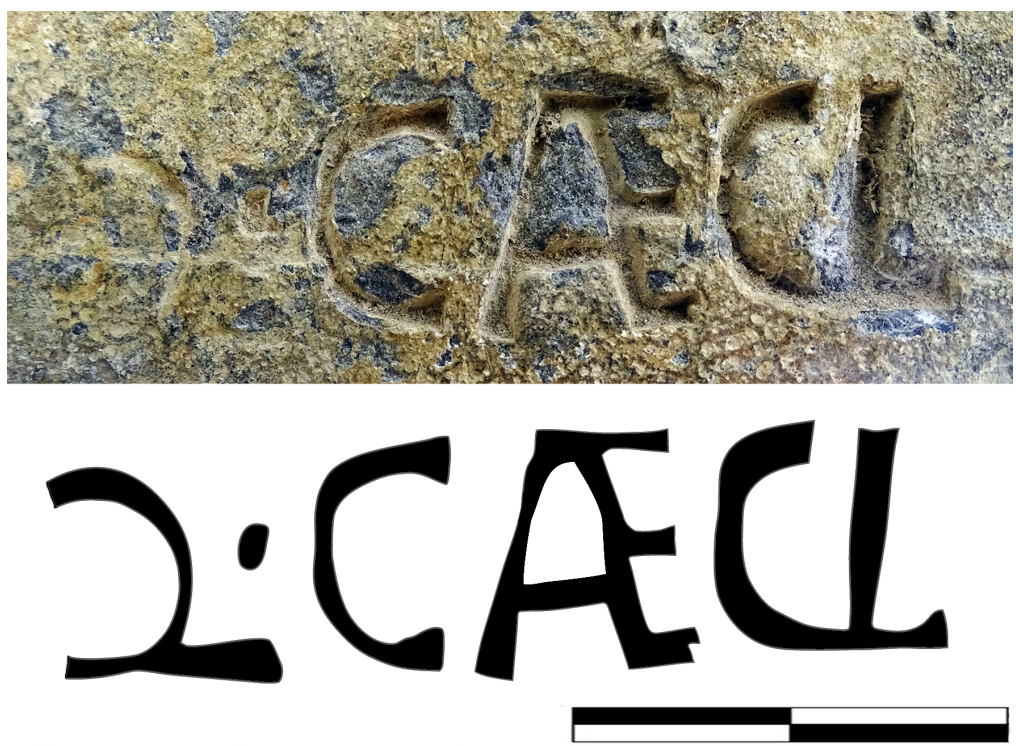

Figura 3. Imagen detallada del resello $Q \cdot C \hat{A} E \widehat{C} \widehat{C} L$, ubicado en la cara A del lingote.

ha apuntado (Colls et al., 1986: 62), coincidimos en que este resello ofrece dos lecturas posibles, ya que puede desarrollarse como Q(uinti) Caecil(ii) o quizá como Q(uintus) Caecil(ius). La segunda opción, sin embargo, parece menos factible, ya que normalmente el nomen utiliza el genitivo cuando aparece entero. En cualquier caso, es uno de los resellos más comunes, junto con el de L•FANNI. De hecho, ambos aparecen en muchas ocasiones impresos en las mismas piezas. Q $\bullet$ CÂEĈ̂IL lo hace marcando diversas series en el pecio Cabrera 5, y todos los lingotes de una misma serie llevan esta marca en algunos casos. Tal no parece ser el caso de la serie de Q $\bullet$ HATERI $\bullet$ GALLI, pues el resello presente en el lingote recuperado del Cabrera 5 era $\mathrm{L} \bullet \mathrm{FANNI}$ y no Q $\bullet$ CÂEĈ̂̂L (véase, tabla 1 ). Sobre cómo interpretar la función de esta marca, han sido propuestas varias opciones. Una primera posibilidad contempla que L. Fannius y Q. Caecilius hubiesen formado equipo (Colls et al., 1986: 70; Domergue, 1994: 75). Posteriormente, el mismo Domergue (1998: 208) matizó esta idea separando entre un primer mercator, que reúne los lingotes de uno o más productores (Q. Caecilius) —aunque en una ocasión también actúa como segundo mercator (Rico, 2011: 49)-, y un segundo que se hace cargo de la mercancía en el puerto de salida (L. Fannius). La tercera posibilidad, sugerida por Rico (201 1: 47-52), resulta de gran interés, aunque complica ligeramente el esquema propuesto por Domergue. Según Rico, en el antes mencionado puerto de salida habría existido un sistema de almacenamiento gestionado por mayoristas en el que los lingotes de distintas procedencias (productores y mercaderes) se guardaban durante cierto tiempo hasta que un comerciante, L. Fannius en el caso del Cabrera 5, los adquiriese para su cargamento, momento en que los marcaba. 
Tabla 1. Distribución de sellos y resellos presentes en las series de lingotes de plomo procedentes del pecio Cabrera 5 y del lingote de la Colección Guerra (Domergue, 1994: tabla 3, modificada por el autor)

\begin{tabular}{|c|c|c|c|c|c|c|c|c|c|}
\hline \multirow[b]{2}{*}{ Serie } & \multirow[b]{2}{*}{ Sellos Cabrera 5} & \multicolumn{7}{|c|}{ Resellos } & \multirow[b]{2}{*}{ Perf. } \\
\hline & & L.FANNI & Q•CÂEĈ̂̂IL & GI•NI & DEMETRI & Q.P.S & Q•POMP & SATV̂L & \\
\hline 3 & P. CAECILI POPILLI (3) & * & & & & * & * & * & * \\
\hline 6 & HAVE IVLI VERNIO (8) & * & * & & * & * & & & * \\
\hline 2 & TANNIBER (4) & * & * & & * & & & & * \\
\hline 8 & P. POSTVMI RVFI (9) & * & * & & * & & & & \\
\hline 1 & Q. AELI SÂTVLLI (1) & * & & & & & & & * \\
\hline 5 & Q. HATERI GALLI (1) & * & & & & & & & * \\
\hline 7 & PLVMB CA[...] (1) & * & & & & & & & * \\
\hline 9 & M. VALERI ABLON (1) & * & & & & & & & * \\
\hline 4 & L. FLA C. POM (7) & & * & & & & & & \\
\hline \multirow[t]{3}{*}{10} & [...]VS L. F. RVFVS (7) & & & * & & & & & \\
\hline & Sello Col. Guerra & \multicolumn{7}{|c|}{ Resellos Col. Guerra } & \\
\hline & Q. HATERI GALLI (1) & & * & & & & * & & * \\
\hline
\end{tabular}

Los lingotes que no llevan su resello simplemente se añadieron en el último momento para completar la carga, lo que explica por qué no se marcaron.

Si nos centramos ahora en el aspecto formal del resello, parece presentar siempre los mismos dos nexos, ÂE y Ĉ̂IL, además de unas dimensiones muy similares en lo que a tamaño de las letras se refiere: 45,5 mm $\times 11 \mathrm{~mm}$ en el ejemplar del Cabrera 5 y 42,2 $\times 11 \mathrm{~mm}$ en el lingote objeto de estudio. En cuanto a la función de este resello, en principio estamos de acuerdo con lo propuesto por Domergue (1994: 75) cuando sugiere que podría tratarse de uno de los personajes que comercializó los lingotes (tabla 1; fig. 3).

\section{3. $\mathrm{Q} \bullet \mathrm{POM}[\mathrm{P}]$}

La parte visible del resello $\mathrm{Q} \bullet \mathrm{POM}[\mathrm{P}]$ tiene unos $34 \mathrm{~mm}$ de longitud y muy posiblemente, algo ya sugerido en el pasado, deba desarrollarse como Q(uintus) Pomp(eius o -onius) o Q(uinti) Pomp(eii o -onii) (Colls et al., 1986: 65). Un punto de tendencia circular separa la inicial del praenomen y el nomen. Siendo una marca bien conocida (tabla 1) - especialmente, si aceptamos la tesis de que se trata del mismo individuo que marca lingotes en frío con el sello $\mathrm{Q} \bullet \mathrm{P} \bullet \mathrm{S}$, como así parece-, no deja de estar exenta de algunas particularidades que merecen un comentario. En primer lugar, y teniendo en cuenta que la zona en que el resello se localiza no presenta apenas concreciones o corrosión marina que pudiera dificultar la lectura de signos adicionales, nos encontraríamos ante una versión abreviada del sello 

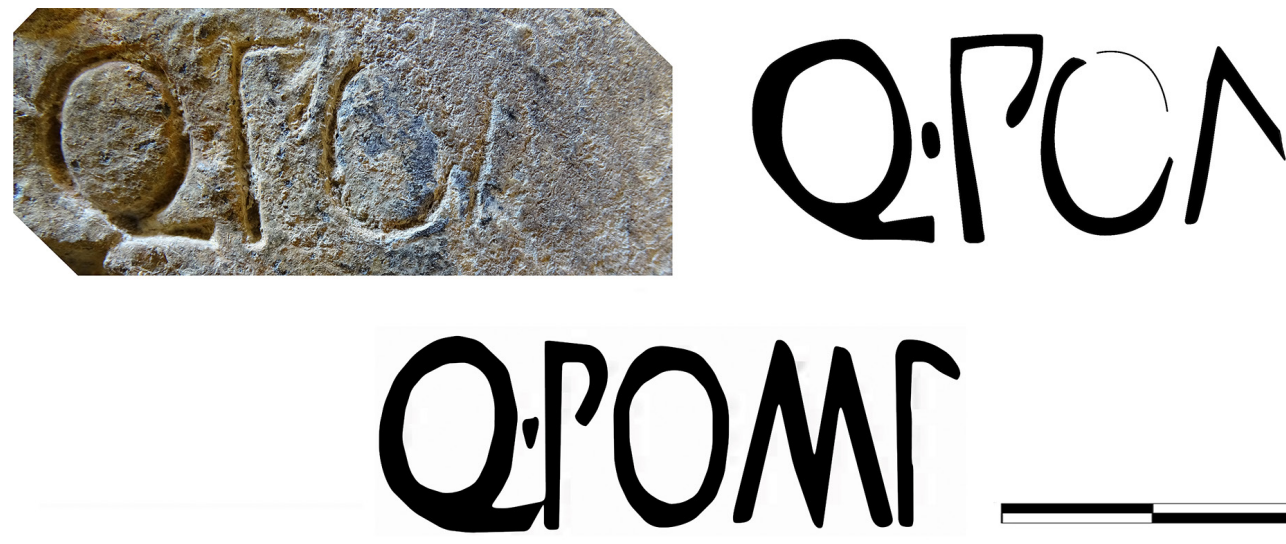

Figura 4. Arriba, fotografía y dibujo del resello $Q \bullet P O M ~ o ~ Q \bullet P O M[P]$, ubicado en la cara $C$ del lingote; abajo, el sello Q•POMP documentado por Colls y otros autores (1986: fig. 10.3).

$(\mathrm{Q} \bullet \mathrm{POM})$ o, en otro caso, el último signo $\mathrm{P}$ no se ha conservado. Esta última posibilidad parece factible si tenemos presente, como se aprecia en la figura 4, que la profundidad de los signos decrece notablemente a medida que avanzamos de izquierda a derecha, lo que quizá obedecería a una presión desigual a la hora de marcar el lingote. Consecuentemente, la profundidad de los trazos es muy pronunciada en la zona en que se ejerció mayor presión $(\mathrm{Q} \bullet \mathrm{P})$, e inferior en los signos realizados con una presión mucho menor $(\mathrm{OM})$, hasta el punto de que el signo final P no se grabó o se marcó de una forma tan superficial que terminó desapareciendo. Esta deficiencia podría haber causado la invisibilidad de un hipotético quinto signo para el que, en teoría, habría espacio suficiente. La hipótesis anterior se ve reforzada por el modus operandi detectado en los lingotes recuperados en las excavaciones del Cabrera 5, cuyas letras — como en el lingote que nos ocupa- muestran una profundidad variable (Colls et al., 1986: 65).

La paleografía de este segundo resello también se asemeja bastante a la documentada en los lingotes del Cabrera 5, puesto que las letras son más bien delgadas, y Q y O tienen forma ovalada, en tanto que el trazo de la P no llega a cerrarse totalmente. Dicho esto, se trata de una matriz distinta a la dibujada por Colls y otros autores (1986, fig. 10.3), ya que los trazos superiores de la $\mathrm{P}$ y el inferior de la Q son más rectos y angulares en nuestro resello. En este, además, no hay contacto entre las letras Q y $\mathrm{P}$, cosa que sí ocurre en el dibujado por Colls y otros autores (fig. 4).

Esta misma marca ha sido documentada en varios lingotes del Cabrera 5 junto con otro resello, SATV̂L. Por eso, se ha sugerido que identifican a un personaje llamado Q. Pomp(eio) o Pomp(onio) Satullo, posiblemente el mismo nombre que se esconde tras el resello $\mathrm{Q} \bullet \mathrm{P} \bullet \mathrm{S}$, también documentado en lingotes del mencionado pecio. Dicho personaje sería el mayorista que suministró los lingotes a L. Fannius y Q. Caecilius (Domergue, 1994: 76-77); es decir, un intermediario que actúa como enlace entre productor y comerciante. 
El hecho de que el resello SATV̂L no aparezca en nuestro lingote, como ocurre en otros casos (tabla 1), no supone un problema a la hora de identificar a un mismo individuo. Un buen ejemplo procedente del mismo pecio son los resellos L • FANNI y DEM̂ETRI, que seguramente se refieren igualmente al mismo personaje, L. Fannius Demetrius, pero que solo aparecen asociados en unos pocos lingotes (tabla 1).

Finalmente, la paleografía de la cartela y los resellos discutidos con anterioridad nos permiten proponer una cronología para el lingote de la Colección Guerra entre finales de la República y la época de Augusto. En la cartela, las interpunciones de tendencia circular, así como el trazo redondeado de la Q, apuntan a esa cronología. Adicionalmente, el hecho de que la P en uno de los resellos sea abierta, incide en que no conviene llevar la cronología de producción del lingote más allá de la época de Augusto, momento en que la P acaba por cerrarse.

\section{Caracterización isotópica}

En el caso que nos ocupa, tenemos un precedente analítico de gran valor, puesto que los lingotes procedentes del pecio Cabrera 5, incluyendo el lingote 5/16 de Q. Haterius Gallus, fueron analizados isotópicamente hace ya casi dos décadas (Trincherini et al., 2001). Las conclusiones de dichos análisis fueron que, muy posiblemente, los lingotes recuperados del pecio procedían del distrito minero conocido como Linares-La Carolina, en Sierra Morena (Trincherini et al., 2001: 401). Tales datos cuadran bien con lo que vemos en la figura 5, que muestra la caracterización isotópica de los lingotes analizados procedentes del Cabrera 5 (Colls et al., 1986: 73, n. ${ }^{\circ}$ de catálogo 2.3, 3.7, 4.10, 5.16, 6.23, 10.40, 1.1, 3.6, 7.25, 8.32 y 9.35) y de varios distritos mineros del sur peninsular, incluyendo Sierra Morena.

\subsection{Metodología analítica}

Los análisis isotópicos fueron realizados por M. Ferrante en el Trace Technologies, en Italia $^{2}$, mediante la utilización de un colector múltiple ICP-MS (MC-ICP-MS) que efectúa mediciones de isótopos de alta precisión. Para llevarlos a cabo, se necesitaron muestras de 0,4 gramos. El tratamiento químico preliminar de las muestras se desarrolló en una sala limpia de clase 100, donde se usó FEP (fluoro-ethylene propylene) ultralimpio en todos los materiales de contención utilizados durante el tratamiento químico. Para optimizar la medición de las relaciones isotópicas con este método, es aconsejable extraer una cantidad de plomo de entre 100 y $500 \mu \mathrm{g}$ de la muestra y, si es posible, separarla de otros elementos presentes haciéndola pasar por microcolumnas que contengan una resina de plomo

2. Agradecemos al Dr. Ferrante que nos facilitase los valores isotópicos de la muestra que, posteriormente, interpretamos para establecer el origen del plomo, por lo que cualquier error es achacable al autor de este trabajo. 
específica (TrisKem, Bruz, F). Con MC-ICP-MS, se puede lograr una precisión superior al $0,001 \%$. En estos análisis, la precisión interna $(2 \sigma)$ de las relaciones isotópicas ${ }^{206} \mathrm{~Pb} /{ }^{207} \mathrm{~Pb}$ $\mathrm{y}{ }^{208} \mathrm{~Pb} /{ }^{206} \mathrm{~Pb}$ fue calculada sobre el promedio de 60 valores adquiridos para la misma medida $(\leq 40 \mathrm{ppm})$.

\subsection{Resultados y origen del metal}

La tabla 2 proporciona los valores de los isótopos de plomo medidos a partir de la muestra tomada del lingote. Las relaciones ${ }^{206} \mathrm{~Pb} /{ }^{207} \mathrm{~Pb},{ }^{208} \mathrm{~Pb} /{ }^{206} \mathrm{~Pb},{ }^{206} \mathrm{~Pb} /{ }^{204} \mathrm{~Pb},{ }^{207} \mathrm{~Pb} /{ }^{204} \mathrm{~Pb}$ y ${ }^{208} \mathrm{~Pb} /{ }^{204} \mathrm{~Pb}$ se utilizan para caracterizar la pieza, que posteriormente se comparará con una base de datos que incluye la caracterización isotópica de minerales de plomo de procedencia cierta y que fueron extraídos en diversas áreas mineras del Mediterráneo activas en la Antigüedad, con el fin de determinar el origen del metal empleado en la elaboración del lingote que aquí nos ocupa (tabla 2).

Por otro lado, los análisis químicos realizados sobre lingotes de plomo romanos obtenidos directamente a partir de la fundición del mineral de galena, como cabe pensar que es el caso del lingote de Q. Haterius Gallus, muestran una pauta uniforme en la que el porcentaje de estaño es siempre muy bajo ( $\leq 0,01 \%$ ) (Wyttenbach y Schubiger, 1973; Domergue et al., 1974: 136). Ello se debe a que el estaño aparece como un elemento traza de forma natural en las minas, pero en la mayoría de los casos lo hace en porcentajes inferiores al $0,01 \%$. En consecuencia, los objetos plúmbeos con niveles altos de estaño normalmente indican que son el resultado del reciclaje de otros objetos (Gomes et al., 2016). En la tabla 3 se puede observar que los valores de estaño presente en el lingote son mínimos.

La figura 5 es un mapa isotópico que proyecta las ratios del ${ }^{206} \mathrm{~Pb} /{ }^{207} \mathrm{~Pb} v$ s. ${ }^{208} \mathrm{~Pb} /{ }^{206} \mathrm{~Pb}$ de la muestra analizada (tabla 2) sobre los ejes $x$ e $y$ de un plano cartesiano. En la gráfica, además, se han añadido, como es habitual, los datos isotópicos existentes para los principales cuerpos minerales peninsulares de los que se extrajo plomo en la Antigüedad: la Sierra de Cartagena (Cartagena/Mazarrón), Sierra Morena y la Sierra de Almagrera (Almería). Adicionalmente, también se han incluido las lecturas isotópicas de los lingotes recuperados en el pecio Cabrera 5 (Trincherini et al., 2001).

Tabla 2. Valores isotópicos del lingote procedente de la Colección Guerra

\begin{tabular}{lcccccccc}
\hline Muestra & 206Pb/207Pb & $\sigma$ & 208Pb/206Pb & $\sigma$ & 206Pb/204Pb & $\sigma$ & 207Pb/204Pb & 208Pb/204Pb \\
\hline Lingote & 1.16767 & 0.00002 & 2.11357 & 0.00079 & 18.18739 & 0.00010 & 15.57575 & 38.44037 \\
\hline
\end{tabular}

Tabla 3. Porcentaje de estaño presente en el lingote procedente de la Colección Guerra

\begin{tabular}{lll}
\hline Muestra & Objeto & $\%$ Sn \\
\hline G1 & Lingote & $<0.0001$ \\
\hline
\end{tabular}




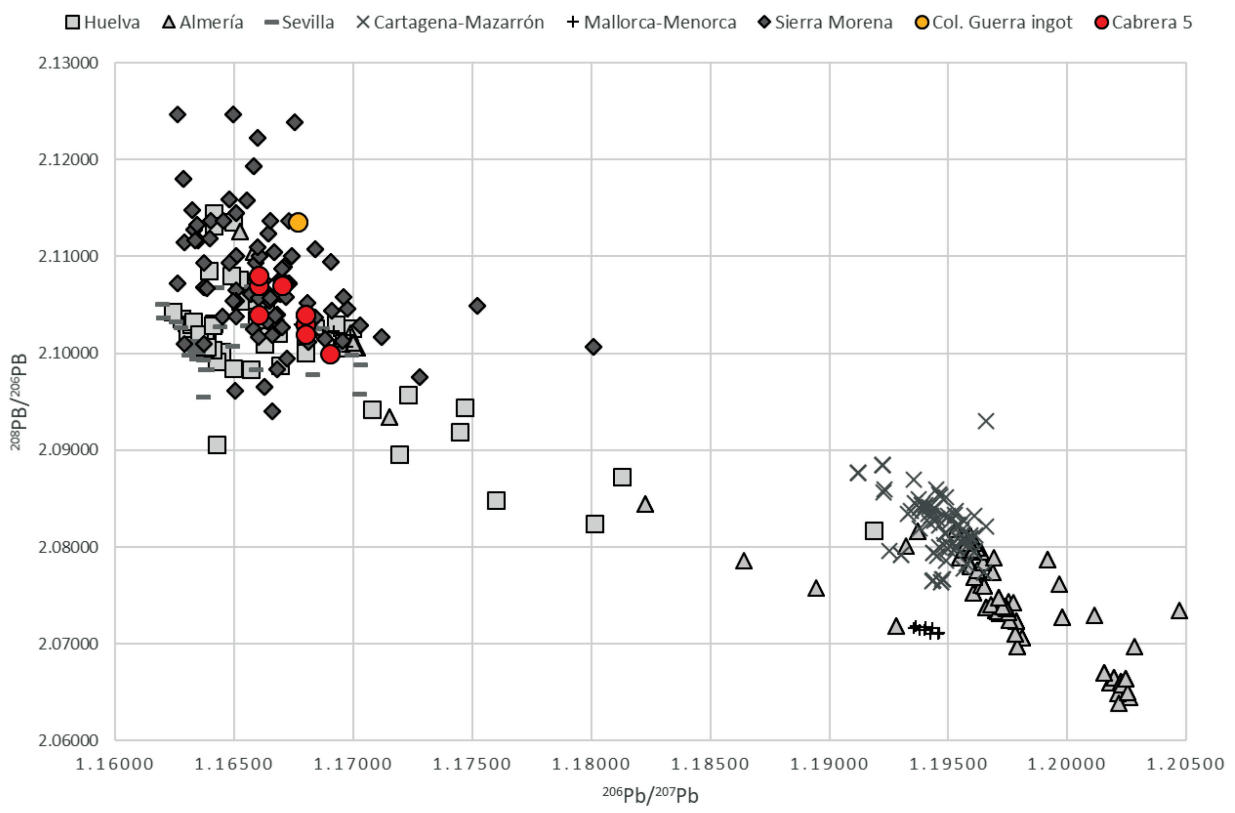

Figura 5. Diagrama binario basado en las proporciones de ${ }^{206} \mathrm{~Pb} / 207 \mathrm{~Pb}$ y ${ }^{208} \mathrm{~Pb} /{ }^{206} \mathrm{~Pb}$ de los lingotes procedentes del pecio Cabrera 5 (Colls et al., 1986: 73, n.o de catálogo 2.3, 3.7, 4.10, 5.16, 6.23, 10.40, 1.1, 3.6, 7.25, 8.32 y 9.35) y del lingote de Q. Haterius Gallus de la Colección Guerra.

Normalmente, las relaciones isotópicas que incluyen a los isótopos de plomo 208-207206 aportan una información más precisa, por lo que el gráfico más habitual en este tipo de estudios es el que compara ${ }^{206} \mathrm{~Pb} /{ }^{207} \mathrm{~Pb} v s .{ }^{208} \mathrm{~Pb} /{ }^{206} \mathrm{~Pb}$. Sin embargo, tener presentes diferentes combinaciones puede ayudarnos a la hora de interpretar las muestras, especialmente cuando la intención es demostrar que el metal puede proceder de una zona específica. Por ello, también hemos incluido en las figuras 6 y 7 los gráficos en los que se compara el ${ }^{207} \mathrm{~Pb} /{ }^{204} \mathrm{~Pb}$ y ${ }^{206} \mathrm{~Pb} /{ }^{204} \mathrm{~Pb}$ y de ${ }^{208} \mathrm{~Pb} /{ }^{204} \mathrm{~Pb}$ y ${ }^{206} \mathrm{~Pb} /{ }^{204} \mathrm{~Pb}$ de los principales cuerpos minerales peninsulares con los del lingote analizado.

Como se aprecia en las figuras 5, 6 y 7, las lecturas isotópicas del lingote de la Colección Guerra concuerdan bien con las ratios conocidas de los minerales de Sierra Morena. Si tenemos en cuenta la localización de las otras inscripciones que mencionan en Hispania a un Haterius y la atribución a este mismo distrito minero de todos los lingotes transportados por el Cabrera 5, incluido el único lingote conocido con el mismo sello, no hay motivos para dudar de dicha adscripción. Adicionalmente, la cronología del pecio Cabrera 5 -inicios del siglo I d. C. (Domergue, 2004: 105) - nos proporciona un excelente dato cronológico de fabricación del lingote y que concuerda perfectamente con la datación propuesta a través de la paleografía. En ese momento, las minas de Cartagena-Mazarrón, tremendamente productivas hasta entonces, entraron en decadencia y dejaron de ser la 


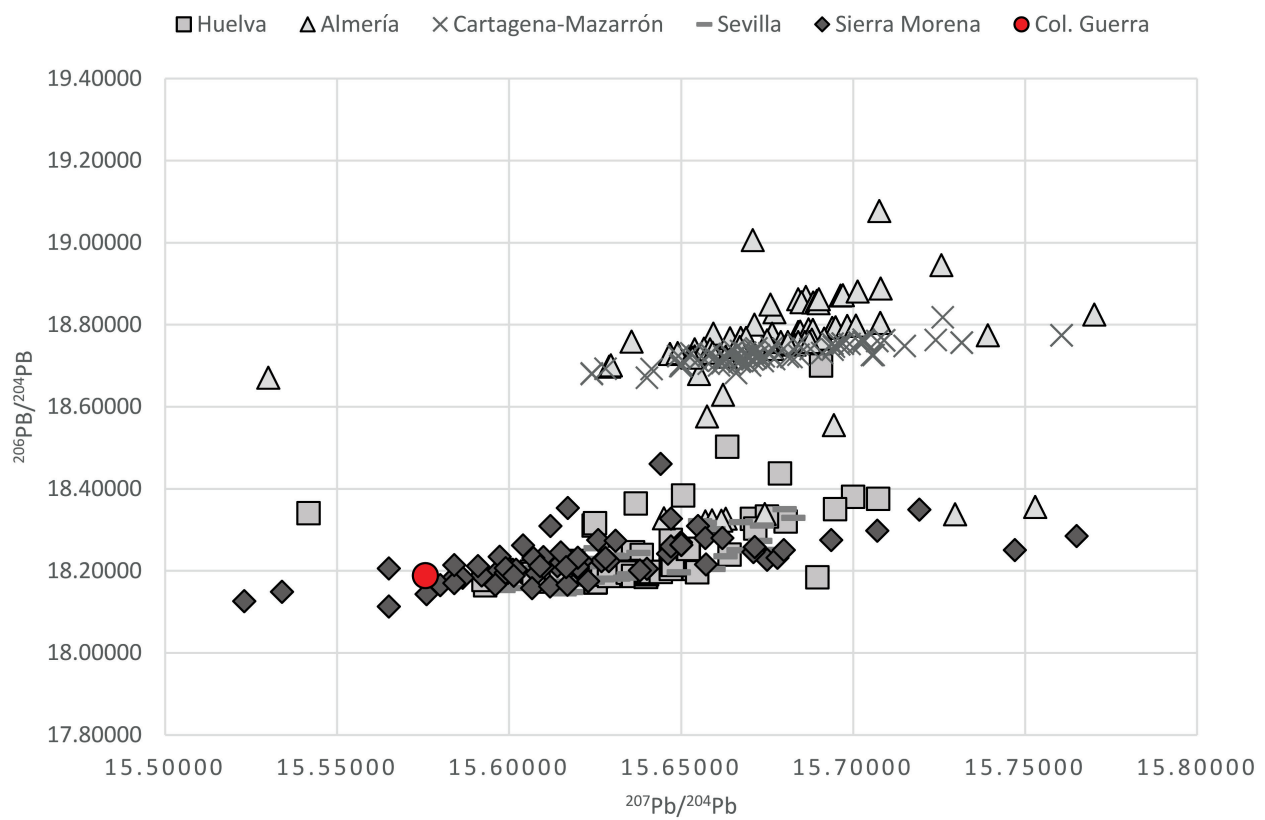

Figura 6. Diagrama binario basado en las proporciones de ${ }^{207} \mathrm{~Pb} /{ }^{204} \mathrm{~Pb}$ y ${ }^{206} \mathrm{~Pb} / 204 \mathrm{~Pb}$ del lingote de Q. Haterius Gallus, de la Colección Guerra.

口Huelva $\triangle$ Almería $\times$ Sevilla $\times$ Cartagena-Mazarrón $\diamond$ Sierra Morena OCol. Guerra

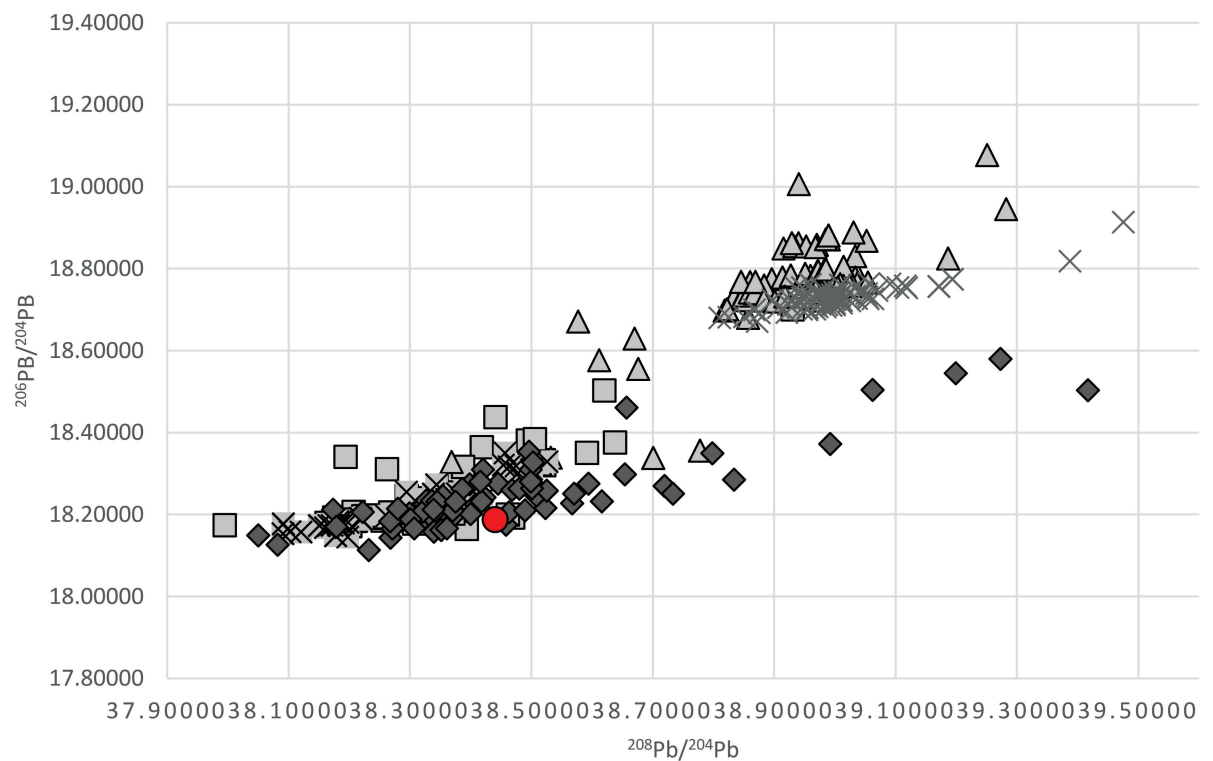

Figura 7. Diagrama binario basado en las proporciones de ${ }^{208} \mathrm{~Pb} /{ }^{204} \mathrm{~Pb}$ y ${ }^{206} \mathrm{~Pb} /{ }^{204} \mathrm{~Pb}$ del lingote de Q. Haterius Gallus, de la Colección Guerra. 


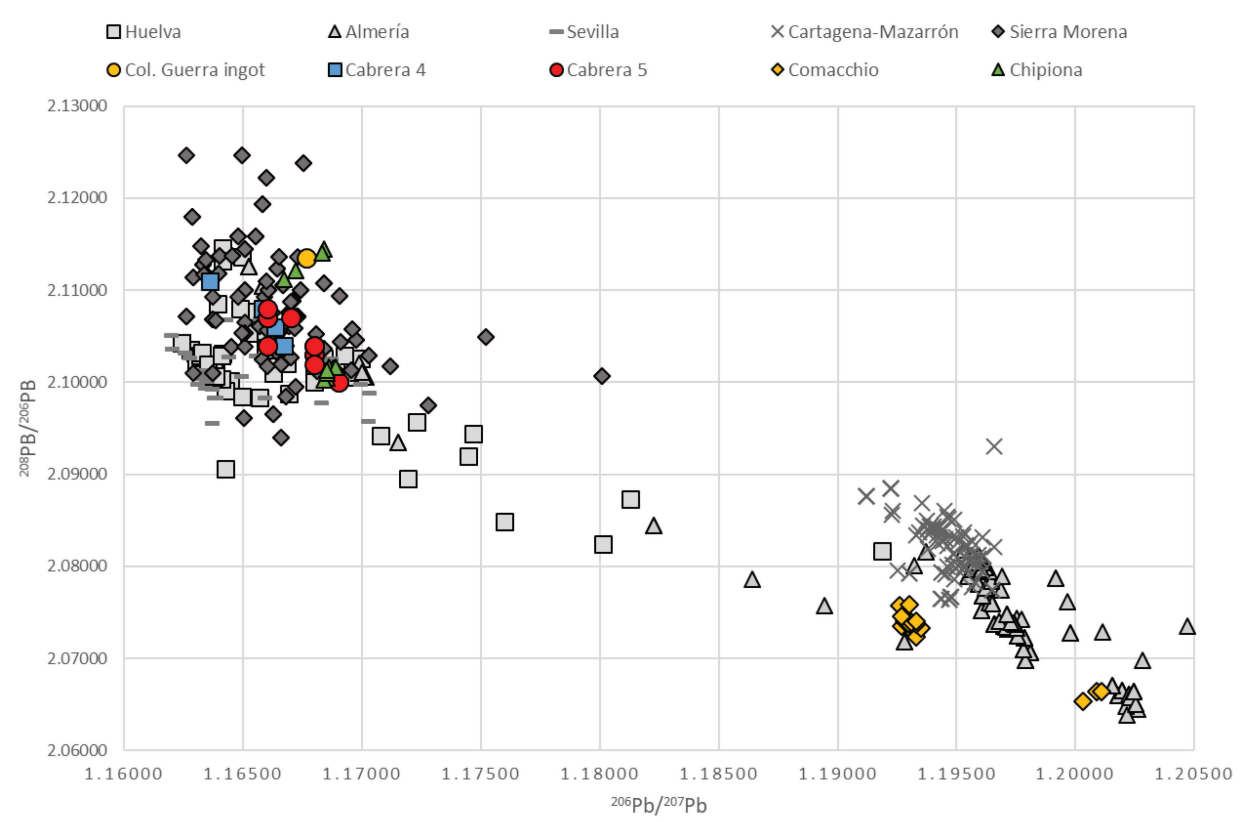

Figura 8. Diagrama binario basado en las proporciones de ${ }^{206} \mathrm{~Pb} /{ }^{207} \mathrm{~Pb}$ y ${ }^{208} \mathrm{~Pb} /{ }^{206} \mathrm{~Pb}$ de los lingotes procedentes de los pecios Cabrera 5 (Colls et al., 1986: 73, n. ${ }^{0}$ de catálogo 2.3, 3.7, 4.10, 5.16, 6.23, 10.40, 1.1, 3.6, 7.25, 8.32 y 9.35; Trincherini et al., 2001), Cabrera 4 (Domergue et al., 2012a), Comacchio (Domergue et al., 2012b), Chipiona (Nesta et al., 2011) y del lingote de Q. Haterius Gallus, de la Colección Guerra.

principal fuente de plomo hispano, en beneficio de las explotaciones de Sierra Morena, que incrementaron notablemente su producción (Orejas y Rico, 2015) (fig. 8).

Si comparamos los valores de nuestro lingote con los resultados de la caracterización isotópica de los lingotes recuperados en las excavaciones del pecio Cabrera 5, incluida la del único ejemplar existente con el mismo sello, un detalle llama la atención: los dos lingotes con el sello $\mathrm{Q} \bullet \mathrm{HATERI} \bullet \mathrm{GALLI}$ fueron elaborados con metal extraído en Sierra Morena, pero no presentan unos valores isotópicos especialmente cercanos (fig. 5). De hecho, existe mayor similitud entre cualquiera de los lingotes procedentes del Cabrera 5 analizados que entre los dos mencionados ejemplares sellados por Q. Haterius Gallus. Para explicar este fenómeno, se ha elaborado un mapa isotópico (fig. 8) que incluye varios conjuntos de lingotes recuperados en pecios con cronologías similares -entre Augusto y mediados del siglo I d. C.- (Trincherini et al., 2001; Domergue et al., 2012a; Domergue et al., 2012b) a las sugeridas para el pecio Cabrera 5 y el lingote de la Colección Guerra. La norma es que los lingotes procedentes de un mismo pecio tiendan a presentar valores isotópicos similares, agrupándose de forma más o menos homogénea. No obstante, como se aprecia en la figura 8 (Chipiona y Comacchio), es frecuente que formen uno o más clústeres con valores isotópicos algo diferentes. Sin ir más lejos, uno de los cuatro lingotes 
analizados procedentes del Cabrera 4 se aleja ligeramente del resto. En resumen, pensamos que la caracterización isotópica del lingote es perfectamente compatible con la hipótesis de que el lingote perteneciente a la Colección Guerra formó parte en su día del cargamento transportado por el Cabrera 5.

\section{Los Haterii: ¿una familia senatorial involucrada en la explotación de las minas de Sierra Morena?}

En su día, Domergue ya valoró la posibilidad de que existiese una conexión entre el Haterius Gallus productor de lingotes y el célebre orador (Sen. Ep. 40.10) y cónsul sufecto del año 5 a. C. (Tac. Ann. 2.33):

Faut-il rapprocher notre producteur de plomb de Q. Haterius, orateur connu du temps de Tibère, consul suffect en 5 av. J.-C., décédé en 26 de notre ère ? Rien ne permet de le faire. Cependant il ne serait pas impossible qu'un affranchi de ce personnage ou d'un de ses fils ait exploité, pour son propre compte ou pour celui de son patron, des mines dans la Péninsule ibérique, mais cela reste une hypothèse (Colls et al., 1986: 53, nota 82).

En 1982, Syme publicó un estudio dedicado exclusivamente a dilucidar por qué se permitió a Rubellius Blandus contraer matrimonio con la sobrina del emperador Tiberio (Tac. Ann. 13.34). En ese mismo trabajo, el autor dejó patente que el enlace entre Quintus Haterius y una de las hijas de Agripa no era más sencillo de explicar (Syme, 1982: 78-79, 1986: 144-145). Es cierto que Tiberio destacó por la facilidad con que promocionó novi homines en algunos momentos de su vida, pero aun así, y en palabras del propio Syme (1986: 145): “¿Quién era Quintus Haterius para ser digno de la sobrina-nieta del emperador Augusto?».

Syme puso de relieve el hecho de que algunos de los oradores que Séneca menciona, Rubellius Blandus y Quintus Haterius entre ellos, dotaron a sus familias de un renombre que sus hijos explotarían (Syme, 1982: 79). No obstante, se ha prestado poca atención en explicar cuáles pudieron ser las estrategias sociales y políticas, así como el origen del patrimonio, que permitieron el ascenso de los Haterii durante tres generaciones hasta que Quintus Haterius Antoninus, nieto de Quintus Haterius, dilapidó la fortuna familiar, hasta el punto de necesitar recibir un estipendio anual asignado por el emperador Nerón (Tac. Ann. 13.34). Como espero demostrar a continuación, es posible que los lingotes marcados con el sello Q $\bullet$ HATERI•GALLI y el matrimonio entre Quintus Haterius y una de las hijas de Agripa sirvan para responder algunas de estas cuestiones.

Llama la atención que los Haterii tuvieran su momento de apogeo en el tránsito de la República al Imperio, alcanzando el hijo (Decimus Haterius Agrippa) y el nieto (Quintus Haterius Antoninus) de Quintus Haterius el consulado en los años 22 y 53 d. C., respecti- 
vamente (Tac. Ann. 3.52, 12.58). Este es el mismo lapso de tiempo en que ubicamos paleográficamente el lingote de la Colección Guerra y en el que se hundió el pecio Cabrera 5 conteniendo, al menos, un lingote con la marca Q•HATERI•GALLI (Domergue, 2004: 105).

No menos interesante resulta el hecho de que Quintus fuera uno de los praenomina más característicos de esta familia senatorial (Tac. Ann. 4.61) y que fuese ampliamente adoptado por varios de sus libertos, así como por los esclavos que estos manumitieron. Buenos ejemplos de ello son Quintus Haterius Evagogus (primera mitad del siglo I d. C.) o Quintus Haterius Tychicus - ya en los inicios del siglo II d. C.—, ambos relacionados con el negocio de la construcción (Lancaster, 2005: 19). El primero ocupó el cargo de decurión en el collegium fabrum tignuariorum (CIL VI, 09408), mientras que el segundo podría ser el mismo individuo cuyos restos reposaron en la famosa tumba de los Haterii ubicada en la antigua Vía Labicana (Sinn y Freyberger, 1996; Trimble, 2018). El hecho de que el productor que sella nuestro lingote utilizase el praenomen Quintus es, por tanto, significativo, como también que no mencione su filiación ni su tribu, lo que podría indicar que se trataba de un liberto, aunque esto último no es posible asegurarlo. Si bien es cierto que el cognomen no es de origen griego, también lo es que no todos aquellos que portaban cognomina griegos formaban parte de los niveles serviles de la población (Bruun, 2013). Tampoco es extraño encontrar esclavos y libertos con nombres latinos. Por ejemplo, entre los esclavos y libertos emeritenses, un 57,5 \% tienen nombres latinos y un $40 \%$ nombres griegos (Edmondson, 2018: 192).

En realidad, Haterius no es un nomen especialmente frecuente, y eso permite llevar a cabo un estudio prosopográfico. Entre la fundación de la República y la caída del Imperio romano de Occidente, tan solo encontramos 70 inscripciones que mencionan a Haterii y que, como ya hemos comentado con anterioridad, se concentran principalmente en el Lacio (Roma), la Campania y en la provincia de Africa Proconsularis ${ }^{3}$. En esta, no obstante, no encontramos ninguna inscripción mencionando un Haterius anterior a los inicios del siglo II d. C. Ello dificulta la asociación de nuestro Quintus Haterius Gallus con esta provincia; especialmente, si tenemos en cuenta que son pocos los Haterii africanos documentados hasta la fecha y que utilizan el praenomen Quintus, como por ejemplo Q. Haterius Securus y Q. Haterius For(¿tunatus?) de Thamugadi.

Más interesante resulta el hecho de que tan solo haya una inscripción anterior a la muerte del emperador Augusto que mencione a un Haterius que no sea el cónsul sufecto del año 5 a. C. En este caso, se trata de un breve epígrafe procedente de Etruria (CIL XI, 2046 [Perusia]) ${ }^{4}$. También de Etruria nos llega la inscripción CIL XI, 02650 (Saturnia), que menciona a un Q(uintus) Haterius Cleme[ns], aunque es mucho más tardía (primera mitad del siglo III d. C.).

Si ampliamos la búsqueda cronológicamente incluyendo inscripciones hasta el año 100 d. C., obtenemos un total de 25 epígrafes. Cuando a estas restamos las que hacen

3. Epigraphik-Datenbank Clauss / Slaby EDCS. Consulta realizada el 01-05-2020.

4. [-] Haterius C(ai) f(ilius) / annorum XV. 
referencia a Quintus Haterius, su hijo, su nieto o al procónsul de Sicilia, Marcus Haterius Candidus, la cifra se reduce a trece textos. Si, además, obviamos la inscripción procedente de Germania Superior y la de Noricum, el número anterior queda en once textos, todos ellos localizados en Roma y comprendidos cronológicamente entre el cambio de era y el año 100 d. C. ${ }^{5}$ Yendo más allá, este grupo se puede reducir a tan solo siete inscripciones si lo limitamos al período comprendido entre el consulado sufecto de Quintus Haterius (5 a. C.) y el consulado de su nieto, Quintus Haterius Antoninus (53 d. C.). ${ }^{6}$ Es importante recalcar que todos los Haterii pertenecientes a este último grupo portan siempre el praenomen Quintus o Decimus (CIL VI, 01426, 01948, 07558, 09251, 09252, 09408 y 35406). Todo apunta, entonces, a que la inmensa mayoría de los textos de época de Augusto y Tiberio en los que se nombran Haterii hacen referencia a libertos de esta familia, así como a los esclavos que estos manumitieron a su vez, o a los hijos de estos y que ya habrían nacido con la categoría de hombres libres.

A partir de los datos epigráficos, resulta evidente que nuestro Haterius Gallus pareció estar relacionado con Roma. Por tanto, dos escenarios son especialmente factibles.

En primer lugar, podría tratarse de un liberto de los Haterii senatoriales que operaba desde las minas de Sierra Morena, opción que consideramos la más plausible, como veremos a continuación. En segundo lugar, podría haber sido un negocio independiente de los quehaceres de la familia senatorial, originado desde Roma (o incluso desde Sierra Morena) por un liberto o por un ingenuus. Quintus Haterius Evagogus y Quintus Haterius Tychicus, ambos vinculados al negocio de la construcción, constituyen ejemplos de lo anterior. En tal caso, no se deben olvidar los diversos vínculos jurídicos y sociales que la relación patrono-liberto imponía, además de otras formas jurídicas (reforzadas por la dependencia del liberto), como las praepositiones (Porto, 1984; Aubert, 1992 y 1994). Es imposible precisar la forma concreta que esta relación adoptó (suponiendo que se tratara de un liberto), y tampoco su duración en el tiempo, a partir de la sola evidencia de un único lingote. Adicionalmente y como ya apuntó en su día Garnsey (1981), los libertos no solo actuaban como intermediarios, sino que algunos de ellos pudieron gozar de una posición financiera independiente.

Llegados a este punto, el matrimonio entre Quintus Haterius con una de las hijas de Agripa resulta clave para argumentar la posibilidad de que nuestro productor Haterius Gallus se tratara, en efecto, de un agente de la familia senatorial. Además, de confirmarse tal hipótesis, el matrimonio entre Quintus Haterius y Vipsania podría entenderse - en parte al menos, ya que las iniciativas de las grandes familias romanas se insertaban en estrategias muy amplias que trascendían lo puramente material- en el contexto de un amplio conjunto de intereses económicos (incluidos el plomo y la plata hispana) que conectarían a Agripa con los Haterii.

5. Epigraphik-Datenbank Clauss / Slaby EDCS. Consulta realizada el 01-05-2020.

6. En este recuento no se han incluido las inscripciones procedentes de Hispania y que ya se han tratado con anterioridad. 


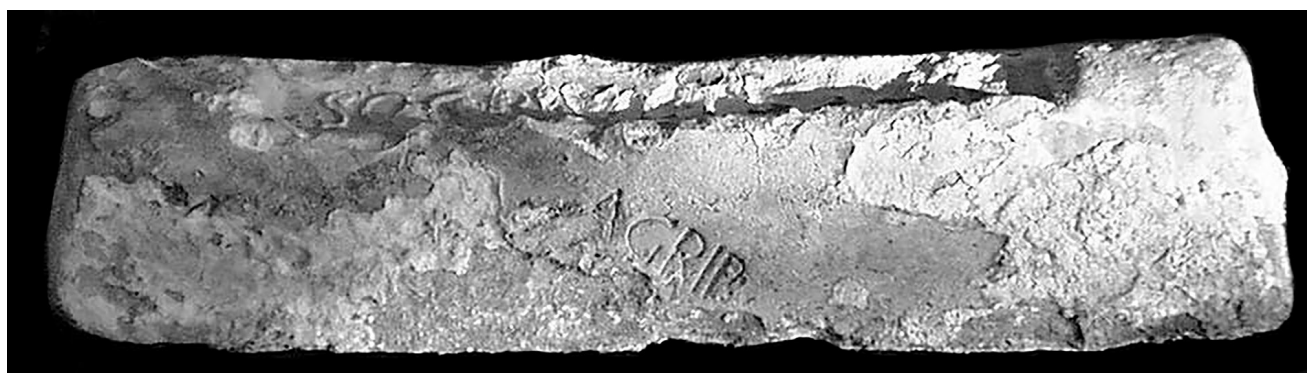

Figura 9. Lingote de plomo con resello AGRIP procedente del pecio de Cap d'en Font (Sant Lluís, Menorca) (De Nicolàs y Rodà, 2002: 1017).

La posible vinculación de Agripa con las minas del sureste peninsular — concretamente, con las explotaciones mineras de Cartagena-Mazarrón y Almería (Sierra de la Almagrera) - es un hecho bien conocido. Así parecen confirmarlo los lingotes resellados con la marca AGRIP, documentados en el pecio Comacchio (Ferrara) (Berti, 1985 y 1986; Domergue, 1987; Domergue et al., 2012b) y en el yacimiento submarino de Cap d'en Font (Sant Lluís, Menorca) —un ejemplar- (De Nicolàs y Rodà, 2002) (fig. 9). El resello de dichos lingotes - los cuales, como en el caso del que aquí nos ocupa, pertenecen al tipo I de Domergue- parece que debe fecharse en época de Augusto. Estudiado en diversos trabajos, todos estos coinciden al afirmar que la marca AGRIP(pa) debe identificarse con el yerno de Augusto, suegro de Quintus Haterius (Berti, 1986; García-Bellido, 1998 y 2000 , entre otros). La adscripción de tales lingotes con las minas del sureste peninsular puede llevarse a cabo con garantías gracias a la información facilitada por la cartela del lingote menorquín —que se interpreta como SOC(ietatis) PLVMB(ariae) [CA]R(thaginiensis) (¿?) (De Nicolàs y Rodà, 2002: 1017) - y a la caracterización isotópica efectuada en el caso de los ejemplares de Comacchio (Domergue et al., 2012b: 81-82 y 88) (fig. 8). Adicionalmente, el hecho de que Agripa fuese patrono de la ciudad de Carthago Nova (1912 a. C.) proporciona un excelente marco histórico para esa asociación (Roddaz, 1984: 414; Keay, 1995: 310).

Agripa estaba implicado en otros tipos de actividades económicas, como la extracción de mármol o la producción de ladrillos (Bruun, 1991: 361-363; García-Bellido, 1998: 39-40, 2000: 691). Por ello, se ha propuesto que la societas plumbaria mencionada en el lingote de Cap d'en Font hubiese estado bajo su control o, lo que parece más factible, que produjese el plomo necesario en las múltiples obras públicas que estaba dirigiendo en Roma (Roddaz, 1984: 249-298; De Nicolàs y Rodà, 2002: 1019) y en las provincias (Roddaz, 1984: 383-418; sobre las inscripciones de M. Agripa (16-15 a. C.) procedentes del teatro de Mérida véase Stylow y Ventura Villanueva, 2018); entre ellas, cabe destacar por su envergadura, la construcción y reparación de acueductos (Suet. Aug. 42), infraestructuras que requieren ingentes cantidades de dicho metal (Bruun, 1991: 104106 y 360-363). 
En consecuencia, si aceptamos la hipótesis de que Quintus Haterius Gallus fue un liberto de Quintus Haterius que dirigía sus negocios - o uno de ellos - en Sierra Morena, no solo documentamos una de las actividades mediante las que esta familia conseguía su riqueza, sino que, además, podremos entender los motivos —al menos, algunos porqués- que justificaron el matrimonio entre Quintus Haterius y la hija de Agripa: el enlace habría supuesto un importante beneficio económico para ambas familias. Al tratarse de minas de galena argentífera, la obtención de plata es el objetivo principal de la explotación minera y su principal fuente de riqueza. La producción de plomo, que como hemos visto también pudo aportar importantes beneficios económicos, debe entenderse como una actividad secundaria.

Gracias a esa unión, Agripa habría extendido su influencia a otro de los principales distritos mineros de la península ibérica, el de Sierra Morena, asegurándose cierto control — de manera más o menos directa- sobre la producción y abastecimiento de una parte de sus riquezas. Cabe ahora recordar que Sierra Morena no tardó en posicionarse como el principal distrito productor y exportador de plomo en Hispania, en detrimento de las minas de Cartagena-Mazarrón, que entraron en decadencia a finales del siglo i a. C. Esta situación parece explicar la estrategia de los Minucii (Díaz Ariño, 2006: 293-294). La actividad de esta gens es atestiguada en Cartagena-Mazarrón gracias al sello [---] PICAE —quizás el Minucius Pica que menciona Varrón (RR 3.2.2) (Domergue y Mas, 1983: 908; Díaz Ariño, 2006: 293)—, documentado en un lingote encontrado en Gacha (Mazarrón), y con mayor certeza con el resello MMIN (Díaz Ariño, 2006), procedente del galápago plúmbeo de Las Amoladeras (Sinner et al., 2020). Posteriormente, los Minucii parecen activos en Sierra Morena (Díaz Ariño, 2006: 293-294), como sugiere el análisis de los lingotes recuperados en el pecio Sud Lavezzi 2 (Liou y Domergue, 1990: 56-94).

Por otra parte, Quintus Haterius no solo pudo establecer lazos familiares directos con la familia imperial gracias a su matrimonio con Vipsania, sino que, posiblemente, con ello también se aseguró una posición privilegiada en la producción, venta y comercialización del plomo que Agripa requiriese para llevar a cabo sus proyectos edilicios y urbanísticos en Roma, con los ingentes beneficios que ello reportaría.

\section{Conclusiones}

En este trabajo hemos presentado un lingote de plomo inédito del productor Q. Haterius Gallus, personaje solo conocido hasta la fecha gracias al sello presente en otro lingote del mismo metal recuperado del pecio Cabrera 5. La aparición de este segundo ejemplar nos ha permitido comparar sus características, epigrafía y caracterización isotópica del metal con el fin de tener un mejor conocimiento de la cronología, fabricación y distribución del plomo hispano del mencionado productor en los inicios del Imperio.

El análisis realizado nos ha ayudado a comprender mucho mejor la historia de este lingote; al menos, desde que se fabricó hasta el momento del naufragio. Basándonos en 
los resellos, podemos constatar que su proceso de comercialización fue muy similar al documentado en los pecios de Sud Perduto 2 y Cabrera 5, y que además los mayoristas $(\mathrm{Q} \bullet \mathrm{P} \bullet \mathrm{S}, \mathrm{Q} \bullet \mathrm{POMP}, \mathrm{SATV} \mathrm{L})-\mathrm{O}$, mejor dicho, el mayorista, si aceptamos las tesis de Domergue (1994: 77) - y los comerciantes $(\mathrm{L} \bullet \mathrm{FANNI}$ y $\mathrm{Q} \bullet \mathrm{CA} E \hat{E} \hat{C} \mathrm{I} L)$ que intervinieron en su distribución y comercialización son los mismos que lo hicieron en las series del Cabrera 5.

Los análisis isotópicos llevados a cabo nos han permitido conocer el origen del metal utilizado en la elaboración del lingote: las minas de Sierra Morena. Los lingotes recuperados en las excavaciones del Cabrera 5 comparten esta procedencia.

Si a lo anterior sumamos el hecho de que actualmente solo se conocen dos lingotes con este sello, y teniendo presente que un número indeterminado de lingotes fueron expoliados durante las excavaciones del Cabrera 5, concluimos que es altamente probable que el lingote de Q. Haterius Gallus, hoy en la Colección Guerra, hubiese formado parte en su momento de la carga transportada por el Cabrera 5. Este dato resulta de gran interés, puesto que contextualiza la pieza arqueológicamente y aporta nueva y relevante información para el estudio de dicho pecio.

Tras realizar un estudio prosopográfico sobre el nomen Haterii, la hipótesis más factible es que Quintus Haterius Gallus, propietario o gestor de la explotación minera ubicada en Sierra Morena y que produjo el lingote objeto de estudio, fuese un liberto de Quintus Haterius - cónsul sufecto del año 5 a. C.— o del hijo de este. Aunque parece mucho menos probable, el mencionado lingote también podría haber sido fruto de un negocio independiente de los quehaceres de esta familia senatorial, emprendido por alguno de los descendientes de sus múltiples libertos, pero ya sin lazos clientelares que lo unieran a la familia del patrón original. No obstante, creemos que los precedentes sobre la implicación de familias senatoriales en la explotación de las minas de Hispania (Díaz Ariño y Antolinos, 2011 ; Díaz Ariño, 2019, entre otros) refuerzan la hipótesis de que el Haterius Gallus de Sierra Morena fue un liberto de los Haterii senatoriales.

Revelar la conexión existente entre las actividades mineras desarrolladas en Hispania y los Haterii en Roma permite documentar un nuevo caso de una familia senatorial con intereses en las minas hispanas, y también aporta nuevos datos para entender el porqué del matrimonio entre Quintus Haterius con Vipsania, la hija de Agripa: tal enlace habría permitido a Agripa extender su influencia a las minas de Sierra Morena.

En definitiva, no parece que el éxito económico y social que Rubellius Blandus (Díaz Ariño, 2019) y Quintus Haterius disfrutaron se debiera exclusivamente a sus capacidades y habilidades como oradores. A esa parte de la ecuación, de la que los textos clásicos nos informan, habría que añadir los nada desdeñables beneficios sociales y económicos que ambos obtuvieron gracias a su participación en la explotación de minas de galena argentífera en Hispania, así como a una clara estrategia por parte de la familia imperial y su círculo más próximo consistente en extender su influencia y, quizá, ganar así el control de las minas de Cartagena y Sierra Morena. 


\section{Agradecimientos}

Quisiera agradecer al Sr. Guerra que me permitiese visitar su colección en varias ocasiones, así como las facilidades y excelente trato que me dispensó en cada una de dichas visitas. También quisiera agradecer a Víctor Revilla (Universitat de Barcelona), Christian Rico (Université Toulouse Jean Jaurès), Borja Díaz Ariño (Universidad de Zaragoza), Jonathan Edmondson (York University), Gregory Rowe (University of Victoria), Robert Knapp (University of California, Berkeley), Albert Martín (arqueólogo municipal de Cabrera de Mar) y a los dos evaluadores anónimos sus comentarios a una versión previa de este artículo, que han permitido mejorar el texto final del mismo.

\section{Bibliografía}

\begin{abstract}
ABASCAL PALAZÓN, J. M., 1994, Los nombres personales en las inscripciones latinas de Hispania. Murcia.
\end{abstract}

AUBERT, J. J., 1992, Workshop Managers, en W. V. HARRIS (ed.), The Inscribed Economy, Roma Ann Arbor, 171-181.

AUBERT, J. J., 1994, Business Managers in Ancient Rome. A Social and Economic Study of Institores 200 BC - $A D$ 250, Leiden.

BEBKO, W., 1971, Les épaves antiques du Sud de la Corse, Cahiers Corsica 1-3, Fédération d'associations et groupements pour les études corses, Bastia.

BERTI, F., 1985, La nave romana di Comacchio, Rivista di Studi Liguri 51, 553-570.

BERTI, F., 1986, L'épave aux lingots de Valle Ponti (Comacchio), en R. CHEVALIER (dir.), Les mines et la métallurgie en Gaule et dans les provinces voisines, Caesarodunum 22, París, 129-136.

BRUUN, C., 1991, The Water Supply of Ancient Rome: A Study of Roman Imperial Administration, Commentationes Humanarum Litterarum 93, Societas Scientiarum Fennica, Helsinki.

BRUUN, C., 2013, Greek or Latin? The Owner's Choice of Names for vernae in Rome, en M. GEORGE (ed.), Roman Slavery and Roman
Material Culture, Phoenix Suppl. 52, University of Toronto Press, Toronto-Buffalo, 19-42.

COLLS, D., DOMERGUE, C. y GUERRERO, V., 1986, Les lingots de plomb de l'épave Cabrera 5 (île de Cabrera, Baléares), Archaeonautica 6, 31-80.

DE NICOLÀS, J. C., y RODÀ, I., 2002, Un nuevo lingote de plomo con la marca AGRIP, en M. MAYER, G. BARATTA y A. GUZMÁN (eds.), XII Congressus Internationalis Epigraphiae Graecae et Latinae: Provinciae Imperii Romani Inscriptionibus Descriptae (Barcelona, 3-8 Septembris 2002), 1017-1020.

DÍAZ ARIÑO, B., 2006, Sello sobre lingote de plomo inédito conservado en el Museo Nacional de Arqueología Marítima de Cartagena, Saldvie 6, 291-295.

DÍAZ ARIÑO, B., 2008, Epigrafía latina republicana de Hispania (ELRH), Edicions de la Universitat de Barcelona, Barcelona.

DÍAZ ARIÑO, B., 2019, Was C. Rubellius Blandus Involved in the Exploitation of the Silver Mines of Carthago Nova?, Historia 68, 228-232.

DÍAZ ARIÑO, B. y ANTOLINOS, J. A., 2011, Una inscripción funeraria republicana procedente de Los Beatos (Cartagena, Murcia), Zeitschrift für Papyrologie und Epigraphik 179, 291-294. 
DOMERGUE, C., 1987, Les lingots de plomb de l'épave romaine de Valle Ponti (Comacchio), Epigraphica 49, 109-175.

DOMERGUE, C., 1990, Les Mines de la Péninsule Ibérique dans l'Antiquité romaine, Roma.

DOMERGUE, C., 1994, Production et commerce des métaux dans le monde romain : l'exemple des métaux hispaniques d'après l'épigraphie des lingots, Actes de la VIIe Rencontre franco-italienne sur l'épigraphie du monde romain (Rome, 5-6 juin 1992), École Française de Rome, Roma, 61-91.

DOMERGUE, C., 1998, A view of Baetica's external commerce in the $1^{\text {st }}$ c. A.D. based on its trade in metal, en S. KEAY (ed.), The archaeology of early Roman Baetica, JRA Suppl. 29, Portsmouth, 201-214.

DOMERGUE, C., 2004, Un parcours a travers les lingoes de plomb romains d'Espagne (1965-2003), Pallas 66, 105-117.

DOMERGUE, C., LAUBENHEIMER, F. y LIOU, B., 1974, Les lingots de plomb de L. Carulius Hispallus. Revue archéologique de Narbonnaise 7, 119-137.

DOMERGUE, C. y MAS, J., 1983, Nuevos descubrimientos de lingotes de plomo romanos estampillados, Crónica del XVI Congreso Arqueológico Nacional, Zaragoza, 905-912.

DOMERGUE, C., QUARATI, P., NESTA, A., OBEJERO, G. y TRINCHERINI, P. R., 2012a, Les isotopes du plomb et l'identification des lingots de plomb romains des mines de Sierra Morena. Questions de méthode : l'exemple des lingots de l'épave Cabrera 4, Pallas 90, 243-256.

DOMERGUE, C., QUARATI, P., NESTA, A. y TRINCHERINI, P. R., 2012b, Retour sur les lingots de plomb de Comacchio (Ferrara, Italie) en passant par l'archéométrie et l'épigraphie, en A. OREJAS y C. RICO (eds.), Minería y metalurgia antiguas. Visiones y revisiones. Homenaje a Claude Domergue, Casa de Velázquez, Madrid, 81-103.

DOMERGUE, C. y RICO, C., 2018,

L'approvisionnement en métaux de l'Occident méditerranéen à la fin de la République et sous le Haut-Empire, en B. WOYTEK (dir.), Infrastructure and Distribution in Ancient Economies, Austrian Academy of Sciences Press, Viena, 193-252.
EDMONDSON, J., 2018, Hacia una historia social de la colonia de Augusta Emerita: problemas metodológicos y perspectivas prometedoras, en E. ORTIZ DE URBINA y J. M. VALLEJO (eds.), Métodos y técnicas en Ciencias de la Antigüedad: estudios sobre investigación y docencia, Servicio Editorial de la Universidad del País Vasco / Euskal Herriko Unibertsitatea Argitalpen Zerbitzua, Anejos de Veleia (Acta 16), Vitoria-Gasteiz, 159-204.

FERRER I JANÉ, J. y SINNER, A. G., 2019, Baitolo, una doble inscripción ibérica en un cepo de ancla de plomo del siglo i a. C., Palaeohispanica 19, 147-167.

GARCÍA-BELLIDO, M. P., 1998, Marcas legionarias y de Agrippa en los lingotes de Comacchio, Epigraphica 80, 9-43.

GARCÍA-BELLIDO, M. P., 2000, Lingots estampillés en Espagne avec des marques de légions et d'Agrippa, en Y. LE BOHEC y C. WOLFF (eds.), Les légions de Rome sous le Haute-Empire, vol. 2, Lyon, 685-698.

GARNSEY, P., 1981, Independent freedmen and the economy of Roman Italy under the Principate, Klio 63, 369-371

GOMES, S. S., VALÉRIO, P., ALVES, L. C., ARAÚJO, M. F. y SOARES, A. M. M., 2016, Tin determination in fistula seals from Conimbriga and Augusta Emerita, Microchemical Journal 124, 540-546.

KAJANTO, I., 1965, The Latin Cognomina, Societas Scientiarum Fennica, Commentationes Humanarum Litterarum XXXVI/2, Keskuskirjapaino, Helsinki.

KEAY, S., 1995, Innovation and Adaptation: The Contribution of Rome to Urbanism in Iberia, Proceedings of the British Academy 86, 291-337.

LANCASTER, L. C., 2005, Concrete Vaulted Construction in Imperial Rome: Innovations in Context, Cambridge University Press, Cambridge.

LAUBENHEIMER, F., 1973, Recherches sur les lingots de cuivre et de plomb d'époque romaine dans les régions de Languedoc-Roussillon et de Provence-Corse, RAN Suppl. 3, París. 
LIOU, B., y DOMERGUE, C., 1990, Le commerce de la Bétique au Ier siècle de notre ère. L'épave Sud-Lavezzi 2 (Bonifacio, Corse du Sud), Archaeonautica 10, 11-123.

MARTÍN MENÉNDEZ, A., 2008, Àmfores Tarraconenses i Bètiques en els derelictes de mitjan de segle I a. C. a la costa catalana, SFECAG, Actes du congrés de L'Escala-Empúries, 103-127.

NESTA, A., KLEIN, S., QUARATI, P., TRINCHERINI, P. R. y RICO, C., 2011, Sobre el origen de los lingotes de Chipiona: aportación del método de isótopos de plomo, Habis 42, 191-208.

OREJAS, A. y RICO, C., 2015, Metalla, civitates, coloniae : les mines hispaniques dans les processus de changement des statuts territoriaux à la fin de la République et au début de l'Empire, Mélanges de l'École française de Rome - Antiquité 127/2, 521-534.

PORTO, A. DI, 1984, Impresa colletiva e schiavo «manager» in Roma antica (sec. II a. C. - II sec. d. C.), Milán.

RICO, C., 2011 , Réflexions sur le commerce d'exportation des métaux à l'époque romaine. La logique du stockage, en J. ARCE y B. GOFFAUX (eds.), Horrea d'Hispanie et de la Méditerranée romaine, Collection de la Casa de Velázquez 125, Madrid, 41-64.

RODDAZ, J. M., 1984, Marcus Agrippa, Bibliothèque des Écoles françaises d'Athènes et de Rome 253, Roma.

SINN, F. y FREYBERGER, K. S., 1996, Die Grabdenkmäler II: Die Ausstattung des Hateriergrabes, Vatikanische Museen, Museo Gregoriano Profano ex Lateranense: Katalog der Skulpturen, vol. I/2, Maguncia.

SINNER, A. G. y FERRER I JANÉ, J., 2020, Baitolo, a native shipowner's vessel, and the participation of northern Iberians in the Laietanian wine-trade under the Late Republic, Journal of Roman Archaeology 33, 365-382.

SINNER, A. G., MARTÍNEZ-CHICO, D. y FERRANTE, M., 2020, El yacimiento subacuático de Las Amoladeras, Cabo de Palos (Cartagena). Nuevos enfoques arqueométricos, Zephyrus LXXXV, 139-162.
STANNARD, C., SINNER, A. G. y FERRANTE, M., 2019, Trade between Minturnae and Hispania in the Late Republic. A Comparative Analysis of the Minturnaean Lead Issues and the Spanish Plomos Monetiformes of the Italo-Baetican Series, and the Numismatic and Epigraphic Evidence of the Trade, Numismatic Chronicle 179, 123-172.

STEFANILE, M., 2017, Dalla Campania alle Hispaniae. L'emigrazione dalla Campania romana alle coste mediteranee della Penisola Iberica in età tardorepubblicana e proto-imperiale, Nápoles.

STYLOW, A. U. y VENTURA VILLANUEVA, Á., 2018, Inscripciones asociadas a la scaena del teatro, en P. MATEOS CRUZ (ed.), La scaenae frons del teatro romano de Mérida, Anejos de Archivo Español de Arqueología 86, Madrid, 157-195.

SYME, R., 1982, The Marriage of Rubellius Blandus, The American Journal of Philology 103/1, 62-85.

SYME, R., 1986, The Augustan Aristocracy, Clarendon Press, Oxford.

TRIMBLE, J., 2018, Figure and ornament, death and transformation in the Tomb of the Haterii, en N. DIETRICH y M. SQUIRE (eds.), Ornament and Figure in Graeco-Roman Art: Rethinking Visual Ontologies in Classical Antiquity, Walter de Gruyter, Berlín, 327-352.

TRINCHERINI, P. R. y FACCHETTI, S., 1983, Isotope Dilution Mass Spectrometry applied to lead determination, en S. FACCHETTI (ed.), Analytical Techniques for Heavy Metals in Biological Fluids, Elsevier, Ámsterdam.

TRINCHERINI, P. R., BARBERO, P., QUARATI, P., DOMERGUE, C. y LONG, L., 2001, Where Do the Lead Ingots of the Saintes-Maries-de-la-Mer Wreck Come from? Archaeology Compared with Physics, Archaeometry 43/3, 393-406.

WHITTICK, G. C., 1961, The Casting Technique of Romano-British Lead Ingots, The Journal of Roman Studies 51, 105-111.

WYTTENBACH, A. y SCHUBIGER, P. A., 1973, Trace element content of Roman lead by neutron activation analysis, Archaeometry 15/2, 199-207. 
